INFLUENCE OF DILUTE IMPURITIES ON THE EVOLUTION OF DEFECT CASCADES IN NICKEL*

\author{
J. S. Vetrano \\ Pacific Northwest Laboratory \\ Richland, WA 99352 \\ I. M. Robertson \\ DE92 019585 \\ Department of Materials Science and Engineering \\ University of Illinois, Urbana, IL 61801 \\ M. A. Kirk \\ Materials Science Division \\ Argonne National Laboratory, Argonne, IL 60439
}

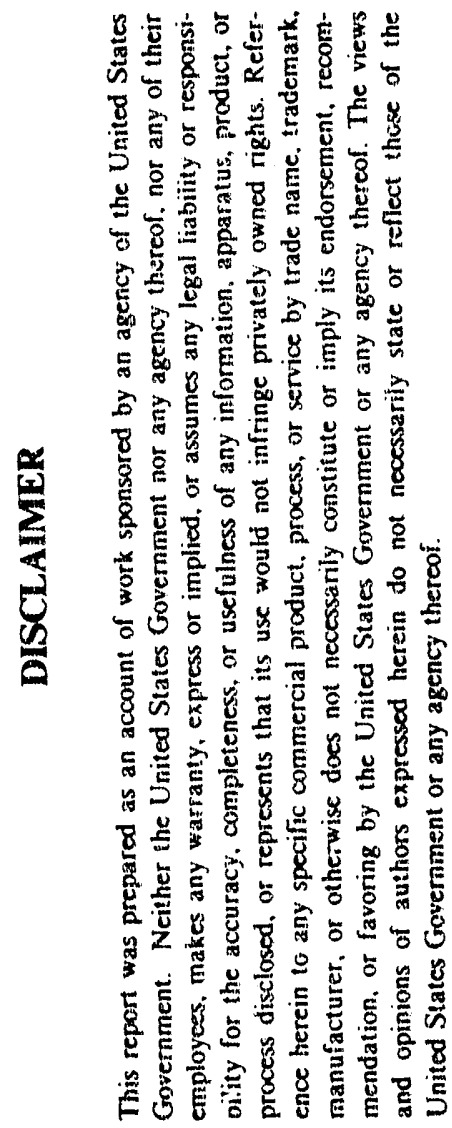

April 1992

\begin{abstract}
The subrnitied manuscriat has boen authred by a santractor of the U.S. Government under contiact

No. W.31-102-ENG.38. Acoordingly, the US.

Government relains a nonexchisive, royalty-lice

likense to publish or reprosuce the publisties form

of this contribution, a allow athers to do so, lor

U.S. Covernmem aurases.
\end{abstract}

Received by OSTI

AUO 241992

Submitted to the Conference on Evolution of Microstructure in Metals During Irradiation, September 29.October 2, 1992, Chalk River, Canada.

*Work supported by the U. S. Department of Energy-BES, contracts DEFG02-91ER45439 (U of 1 ) and W-31-109-Eng-38 (ANL).

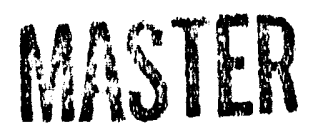




\title{
INFLUENCE OF DILUTE IMPURITIES ON THE EVOLUTION OF DEFECT CASCADES IN NICKEL
}

\author{
L.S. Vetrano*, I.M. Robertson and M.A. Kirk ${ }^{+}$ \\ Department of Materials Science and Engineering, \\ University of Illinois, Urbana II 61801 \\ + Materials Science Division \\ Argonne National Laboratory, Argonne II 60439 \\ *Present address: Pacific Northwest Laboratory \\ Richland WA 99352
}

We have employed transmission electron microscopy to study the formation of vacancy dislocation loops from defect cascades produced by a 50 $\mathrm{keV} \mathrm{Kr}{ }^{+}$ion irradiation of $\mathrm{Ni}$ and its dilute alloys with $\mathrm{Si}$ and $\mathrm{Al}$. An unusual and reproducible dependence of the loop collapse probabilities and loop size distributions on solute content was found. The results are explained by impurity caused changes in both the collisional and thermal spike (molten zone) phase of the defect cascade. Specific mechanisms include disruption of focussons by impurities to change the energy density profile within the collision cascade, interruption of replacement collision sequences, and iriterstitial trapping to reduce recombination during the thermal spike phase. Applying these mecharisms to a statistical distribution of the spatial extent of cascades and to the melt-zones, all the experimental observations can be explained.

\section{Introduction}

Developing an understanding of the basic mechanisms controlling the formation of vacancy loops from displacernent cascades is of fundamental importance as they play a role in void swelling, irradiation creep and embrittlement ${ }^{1,2}$. In this pape: we report on the effect of adding undersized and oversized solute atoms to $\mathrm{Ni}$ on the vacancy loop formati. . p probability and show how such studies allow the physics of cascade collapse to be probed.

Previous studies of solute affects on the loop formation probab:lity in $\mathrm{Ni}$ show complex trends. Robinson and Jenkins ${ }^{3}$ found that the addition of $\leq 17 \%$ $\mathrm{Cr}$ to $\mathrm{Ni}$ reduced the defect yield (which is defined as the fraction of displacement cascades that form a defect) by as much as $60 \%$ when $80 \mathrm{keV} \mathrm{Ni}{ }^{+}$ions were used for the irradiation. No dependence of the defect yield on the alloy content was found when $80 \mathrm{keV} \mathrm{W}^{+}$ions were used for the irradiation. The average defect 
image size increased with increasing ion mass, but no dependence on alloy concentration was found. Robinson and Jenkins ${ }^{3}$ attributed the defect yield reduction observed in the alloys irradiated with $\mathrm{Ni}^{+}$ions to a decrease in the loop nucleation probability in the cascade core. They suggested that the similarity in the image sizes indicated that loop growth by the accretion of vacancies was similar in all alloys.

Shoaib et al ${ }^{4}$ irradiated dilute $(<7 \%) \mathrm{Ni}-\mathrm{Si}$ and $\mathrm{Ni}-\mathrm{C}$ alloys with $100 \mathrm{keV} \mathrm{Ni}^{+}$ ions at room temperature. They found that the defect yield initially decreased as $\mathrm{Si}$ was added, and reached a minimum at 0.71 at \% Si before it increased. A similar behavior was found in the Ni-C alloys. They attributed these changes in the defect yield to the solute elements dechanneling replacement collision sequences and to them acting as heterogeneous nucleation sites for vacancy loops. As the solute content was increased the latter effect dominated and, hence, the increase in the defect yield.

In this paper we report on the effect of Si and $\mathrm{Al}$ additions to $\mathrm{Ni}$ on the loop formation probability and defect image size. These solutes were chosen as $\mathrm{Si}$ is undersized and $\mathrm{Al}$ is oversized in the Ni lattice. They are therefore expected to have different trapping strengths. The microstructure produced by a $50 \mathrm{keV} \mathrm{Kr}^{+}$ ion irradiation was characterized by using transmission electron microscopy techniques. The observations are interpreted in terms of the molten-zone model for vacancy loop formation, which is based on molecular dynamic computer simulations of low-energy displacement cascades ${ }^{5-10}$. These simulations have shown that in $\mathrm{Cu}$ and $\mathrm{Ni}$ the central portion of the cascade is molten. Although loop formation was not found in the simulations, it was proposed that if the solidification rate was slow, vacaricies would be formed toward the end of the solidification process and in the cenier of the molten zone volume ${ }^{6.8}$. This condition would favor loop formation. This model of vacancy loop formation has been used successfully to explain qualitatively the different defect yields in copper and nickel ${ }^{2.11 .12}$, the decrease in the defect yield vith decreasing irradiation temperature ${ }^{12}$ and the loss, coalescence of loops that occurs as the ion dose is increased $\mathrm{d}^{12}$.

\section{Experimental Procedures.}

The alloys used in this study were produced by arc-melting high-purity elements in a flowing Argon gas environment. The inductively coupled plasma analysis technique was used to determine the impurity content of the alloys, no significant level of any impurity was found. TEM discs were annealed at $900^{\circ} \mathrm{C}$ in vacuum for 12 hours before being jet electropolished to perforation.

Electron transparent discs were irradiated at room temperature with $50 \mathrm{keV}$ $\mathrm{Kr}^{+}$ions. Samples of the different alloys were irradiated in the same batch, which 
eliminated the need for accurate ion dosimetry. The damage structure was examined by using the transmission electron microscope. Details of the procedures used to determine the defect yield and to measure the defect image size are described elsewhere ${ }^{13}$.

\section{Experimental Results.}

In Figure 1 micrographs showing the damage structure produced in the alloys after a room temperature irradiation to an ion dose of $6 \times 10^{11}$ ions $\mathrm{cm}^{-2}$ are compared. Qualitatively, it can been seen that the highest defect density occurs in the $\mathrm{Ni}-0.5 \%$ Al (Figure $1(\mathrm{~d})$ ) and $\mathrm{Ni}-0.6 \% \mathrm{Si}(1(\mathrm{~b})$ ) alloys, and that the largest defects form in the $\mathrm{Ni}-7 \% \mathrm{Al}(\mathrm{q}(\mathrm{f}))$ and the $\mathrm{Ni}-4 \% \mathrm{Si}(1(\mathrm{c}))$ alloys. The dependence of the defect yield on the alloy content is quantified in Figure 2 where the defect yield is plotted as a function of the alloy content. It is worth noting that each data point was generated from at least 10 micrographs taken from two different samples and that the total error from the beam inhomogeneity and the microscopy was about $10 \%$. Therefore, the reported defect yield differences are outside the combined experimental errors and are significant. Figure 2 shows the complexity of alloying effects, the defect yield initially increases and then decreases as more solute is added. In the Ni-Al system, the defect yield in the high solute content alloys is less than in pure nickel.

The effect of the arnount of alloying element on the defect image size is shown more clearly in the image size distributions presented in Figures 3 and 4 for the $\mathrm{Ni}-\mathrm{Si}$ and the $\mathrm{Ni}-\mathrm{Al}$ alloys, respectively. The distribution from pure $\mathrm{Ni}$ is included in both figures for purposes of comparison. From these distributions it can be seen that the average defect size increases only in the $\mathrm{Ni}-4 \% \mathrm{Si}$ and the $\mathrm{Ni}-7 \% \mathrm{Al}$ alloys. The average defect size was $2.15 \mathrm{~nm}$ in Ni compared to 2.8 and $2.59 \mathrm{~nm}$ in the $\mathrm{Ni}-4 \% \mathrm{Si}$ and the $\mathrm{Ni}-7 \% \mathrm{Al}$ alloys, respectively. Also, larger defects were present in the alloys compared to pure Ni. The largest defect observed in $\mathrm{Ni}$ had an image diameter between 4.5 and $5.0 \mathrm{~nm}$ whereas in the $\mathrm{Ni}-4 \% \mathrm{Si}$ and $\mathrm{Ni}-7 \% \mathrm{Al}$ the largest defects had an image diameter between 7.0 and $7.5 \mathrm{~nm}$.

The loop Burgers vector distributions were similar in all alloys. Typically, about 2/3 of the visible defect loops could be unambiguously assigned a Burgers vector. Of that population about $80 \%$ were either Frank loops or Frank loops that had partially dissociated toward a stacking-fault tetrahedra and the remaining $20 \%$ were perfect loops.

\section{Discussion}

Molecular dynamic computer simulations of cascade formation have indicated that a portion of the cascade exists in a molten state for a short time ${ }^{5 \cdot 10}$. 
It is envisioned that as the molten zone solidifies vacancies will be created since there are more lattice sites than atoms; the atoms having been rer noved from the melt-zone during the displacement phase of the cascade. The distribution of vacancies within the melt-zone will depend on the duration of the molten zone, which will depend on the melting temperature of the material and the rate of solidification. For slow solidification rates the vacancies will be created toward the cascade center, which will favor loop tormation.

One prediction of the molten zone model of a displacement cascade is that the duration of the molten zone is dependent on the melting temperature of the material $\left.\right|^{2,6,8}$. When the cascade dynamics are similar, the vacancy loop formation probability is predicted to be higher in the lower melting temperature material. In $\mathrm{Cu}-\mathrm{Ni}{ }^{14.15}$ and $\mathrm{Ag}-\mathrm{Pd}^{15}$ alloys, it has been shown that the loop formation probability decreases for large increases in melting temperature. However, the relationship between the defect yield and melting temperature was not simple. For example in the Cu-Ni system, at $<20 \%$ solute addition the change in the defect yield did not follow the expected trend. For both alloy systems used in this program, the liquidus is shallow and the largest melting temperature decrease is $25^{\circ} \mathrm{C}$ for the $\mathrm{Ni}-4$ at $\% \mathrm{Si}$ alloy. This small reduction ( $2 \%$ ) in melting temperature is not expected to have a dramatic effect on the duration of the meltzone and therefore on the loop formation probability. The following discussion therefore considers how other solute atom effects, such as disruption of focussons and replacement collision sequences and solute-interstitial trapping, can effect the size and duration of the molten zone and, consequently, the loop formation probability and the loop size.

The propagation of replacement collision sequences and focussons will be disrupted by the solute atoms because of the size and mass difference. The interruption of a replacement collision sequence will place the self-interstitials closer to the molten zone. If these interstitials are included in the molten zone then the difference in density between the molten zone and the matrix will be smaller and fewer vacancies will be created. This will cause a decrease in the loop size and, perhaps, the loop formation probability. Although the effect of disrupting replacement collision sequences could account for the observed decrease in defect yield with increasing solute content, it cannot account for the observed increase in defect image size.

The disruption of a focusson chain by a solute atom will cause the energy to be deposited closer to the molten zone. A consequence of this is that the temperature of the volume surrounding the molten zcne will be increased (i.e., the effective energy density will be increased), which will increase the duration of the molten zone ${ }^{10}$. This in turn will promote vacancy agglomeration in the cascade 
center, which will enhance loop formation. By this process the loop formation probability from all sizes of displacement cascades will be increased. The magnitude of this effect can be estimated as follows. For a solute concentration of 0.5 at \%, one in every 200 atoms will be a solute atom. If the average length of a focusson chain is taken to be 30 atoms, then one focusson chain in seven will encounter a solute atom. If we assume that the solute atom is the 15 th atom in the chain, the total number of atoms involved in the propagation of the seven focussons will be reduced from 210 to 195 . This will reduce the effective cascade volume, which we define to include the focusson chain length, by $21 \%$. It is not known how changes of this magnitude will influence the loop collapse probability, but in Ni where only $33 \%$ of the displacement cascades form visible loops small changes could have a profound effect.

Solute atoms can trap self-interstitials, which would prevent then from being pulled into the molten zone. This mechanism would increase the number of vacancies, which in turn would increase the defect yield and the size of the vacancy loop.

From the above discussion it is evident that if only one solute effect is considered, the experimental observations presented in section 3 cannot be accounted for. However, the formation of the displacement cascade is a statistical process and the cascades will exist with a range of volumes. It is therefore necessary to consider the consequences of the different solute atorn effects on this distribution. In considering these effects, it is assumed that the total volume of the molten zone is independent of the volume of the displacement cascrde. Justification for this assumption is provided by the work of Caro et al ${ }^{16}$, who demonstrated that the molten zone volume was dependent on the damage energy, but independent of the cascade volume. They also showed that the volume of the molten zone could be greater than that of the displacement cascade.

For displacement cascades whose volume is just greater than that of the molten zone, the disruption of focussons will increase the temperature of the surrounding volume and, perhaps, the molten zone size. This will cause more interstitials to be brought back to the molten zone, which will decrease the difference between the molten zone and lattice density. Consequently, the number of vacancies left in the center of the molten zone will decrease and the molten zone lifetime will increase. Thes 9 effects will have the greatest impact on small loops and will produce more loops with a size below the microscope resolution limit. Because of this shift in size of the loops, the defect yield will decrease. For displacement cascades whose volume is significantly greater than that of the molten zone, the interstitials trapped throughout the cascade volume by the solute atoms are removed from the molten zone. The increase in the molten zone lifetime that occurs because of the change in the temperature of the surrounding material will increase the number of vacancies left in the center of the 
molten zone, which will form larger loops.

The experimental observations can be understood as follows: The initial increase in the defect yield with the addition of solute is due to solute elements disrupting focussons, which increases the temperature of the material surrounding the molten zone. This results in an increase in the molten zone lifetime and a concomitant increase in the loop formation probidbility. If this mechanism continues to dominate, the defect yield would increase rather than decrease with increasing solute content. The decrease in the defect yield as the solute level is increased is due to a combination of solute effects: (a) the density difference between the molten zone and the matrix is reduced because interstitials produced nearer the molten zone by the disruption of replacement collision sequences are now included in the molten zone and (b) the temperature of the lattice surrounding the molten zone is increased because of the disruption of focussons. This combination of effects has the greatest impact on displacement cascades whose volume is similar to that of the molten zone, and will reduce the number of loops close to the microscope resolution limit. This decrease in the number of small loops as the solute content increases is seen in the size distributions presented in Figures 3 and 4 . The increase in the density of large loops as the solute sonterit is increased is explained by considering the effect of focusson disruption on the molten zones in displacement cascades whose volume is large compared to that of the molten zone. Here the effect is to increase the lifetime of the molten zone and, hence, increase the number of loops left in tile center at the end of the solidification process, which will increase the size of the loop.

\section{Conclusions}

It has been shown that the effect of increasing the level of $\mathrm{Si}$ or $\mathrm{Al}$ in $\mathrm{Ni}$ caused (a) the defect yield to increase and then to decrease, (b) the densily of loops close to the microscope resolution limit to decrease and (c) the density and overall size of the large loops to increase. These results were explained by considering how solute element effects (i.e., disruption of focussons and replacement collision sequences and solute-interstitial trapping) changed the properties of the molten zone. These changes were then applied to the statistical distribution of cascade volumes and the consequences on the loop formation probability and size were used to explain the experimental observations.

\section{Acknowledgements}

This work was supported by the Department of Energy-BES through grant DEFG02-91ER45439 (U of I) and contract W-31-1090Eng-38 (f NL). We would like to acknowledge use of the electron microscope facilities in the Materials Research Laboratory at the University of Illinois. The authors would like to thank M.W. Bench for the many useful discussions. 


\section{References}

1. N. Igata, Y. Kohno and J. Nishimura, J.of Nucl. Mat. ,14.1-143,(1987),790.

2. C.A. English, J. Nucl. Mat.,134, (1985), 71.

3. T.M. Robinson and M.L. Jenkins, Phil. Mag. A43, (1981), 999.

4. K.A. Shoaib,S.J.H. Bukhari and K. Ehrlich,Dimensional Stability and Mechanical Behaviour of Irradiated Metals and Alloys, Vol. 1 (British Nuclear Energy Society,Loridon, 1983), (1983), 83.

5. T. Diaz de la Rubia, R.S. Averback, R. Benedek and W.E. King, Phy. Rev. Let., 59, (1987), 1930.

6. R. S. Averback, T. Diaz de la Rubia and R. Benedek, Nucl. Instr. and Methods, B33, (1988), 693.

7. T. Diaz de la Rubia, R. S. Averback, H. Hsieh and R. Benedek,J. Mater. Res., 4, (1989), 579.

8. T. Diaz de la Rubia, K.Smalinskas, R.S. Averback, I.M. Robertson and R. Benedek, MRS Symp. Proc., 138, (1989), 29.

9. T. Diaz de la Rubia and M.W. Guinan, J. Nuc. Mat.,174,(1990), 151.

10. Hornming Hseih, T. Diaz de la Rubia, R.S. Averback and R. Benedek, Phys. Rev. B, 40, (1989), 9986.

11. J.S. Vetrano, I.M. Robertson and M.A. Kirk, Scripta Met.,24,(1990), 157.

12. M.A. Kirk, I.M. Robertson, M.L. Jenkins, C.A. English, T.J. Black and J.S. Vetrano, J. Nucl. Mat.,21, (1987), 149.

13. J.S. Vetrano, Ph. D. Thesis, University of Illinois, 1990.

14. K.Smalinskas, M.S. Thesis, Univ. of lllinois, 1988.

15. K.Smalinskas, Gengsheng Chen, J. Haworth, I. M. Robertson and M.A. Kirk, this conference.

16. A. Caro, private communication. 


\section{Figure captions.}

Figure 1. Comparison of the damage structure produced by simultaneously irradiating the different materials to a dose of $6 \times 10^{11}$ ions $\mathrm{cm}^{-2}$ at $300 \mathrm{~K}$. A) Ni, B) $\mathrm{Ni}-0.6$ at. $\% \mathrm{Si}$, C) Ni-4 at. \% Si, D) Ni-0.5 at. $\%$ Al E) Ni-5 at. \% Al and F) Ni- 7 at. $\%$ Al.

Figure 2. Defect yield as a function of alloying content for samples irradiated to a dose of $6 \times 10^{11}$ ions $\mathrm{cm}^{-2}$ at $300 \mathrm{~K}$.

Figure 3. Distribution of the loop image diameters in $\mathrm{Ni}$ and the $\mathrm{Ni}-\mathrm{Si}$ alloys irradiated to a dose of $6 \times 10^{11}$ ions $\mathrm{cm}^{-2}$ at $300 \mathrm{~K}$.

Figure 4. Distribution of the loop image diameters in $\mathrm{Ni}$ and the $\mathrm{Ni}-\mathrm{Al}$ alloys irradiated to a dose of $6 \times 10^{11}$ ions $\mathrm{cm}^{-2}$ at $300 \mathrm{~K}$. 


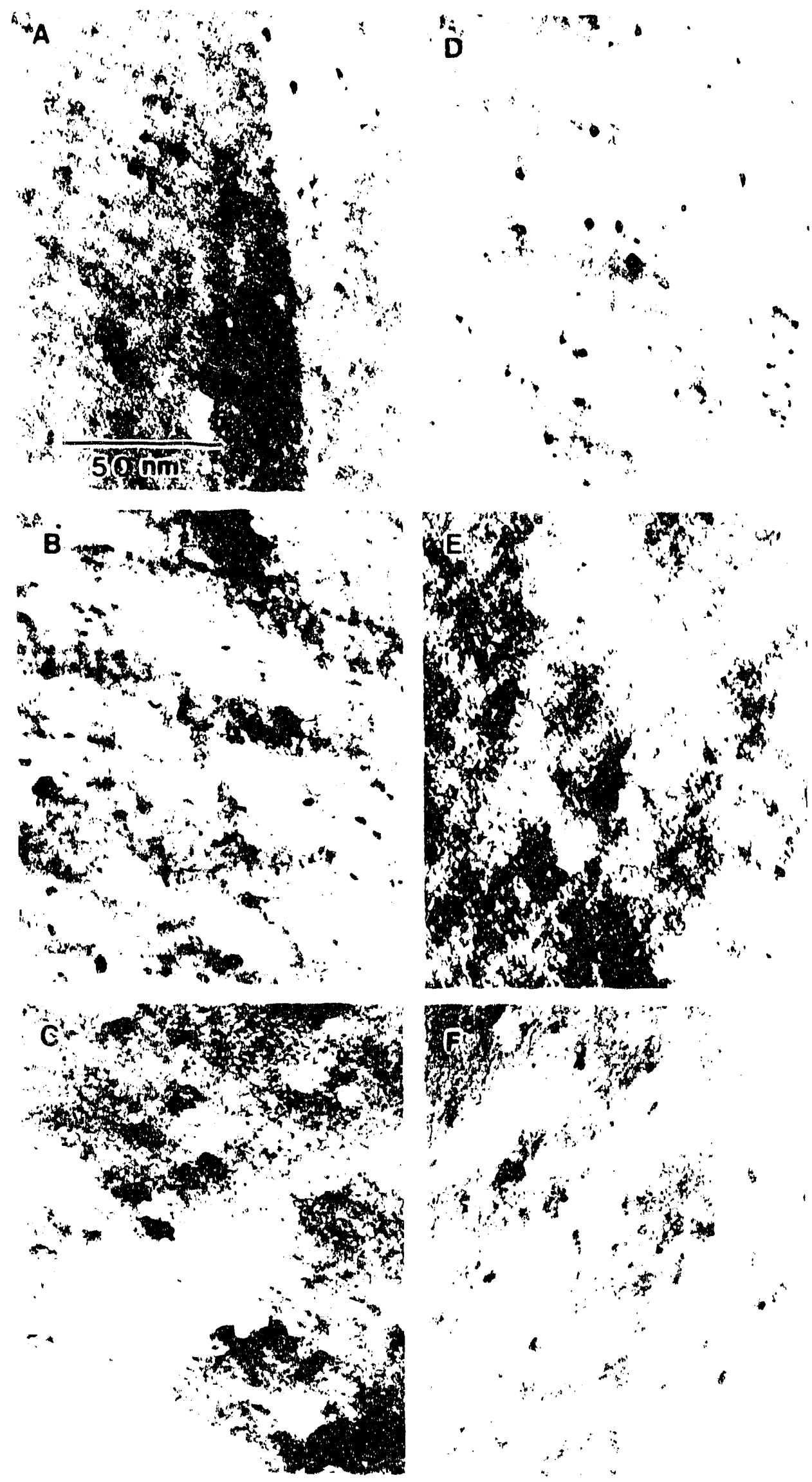




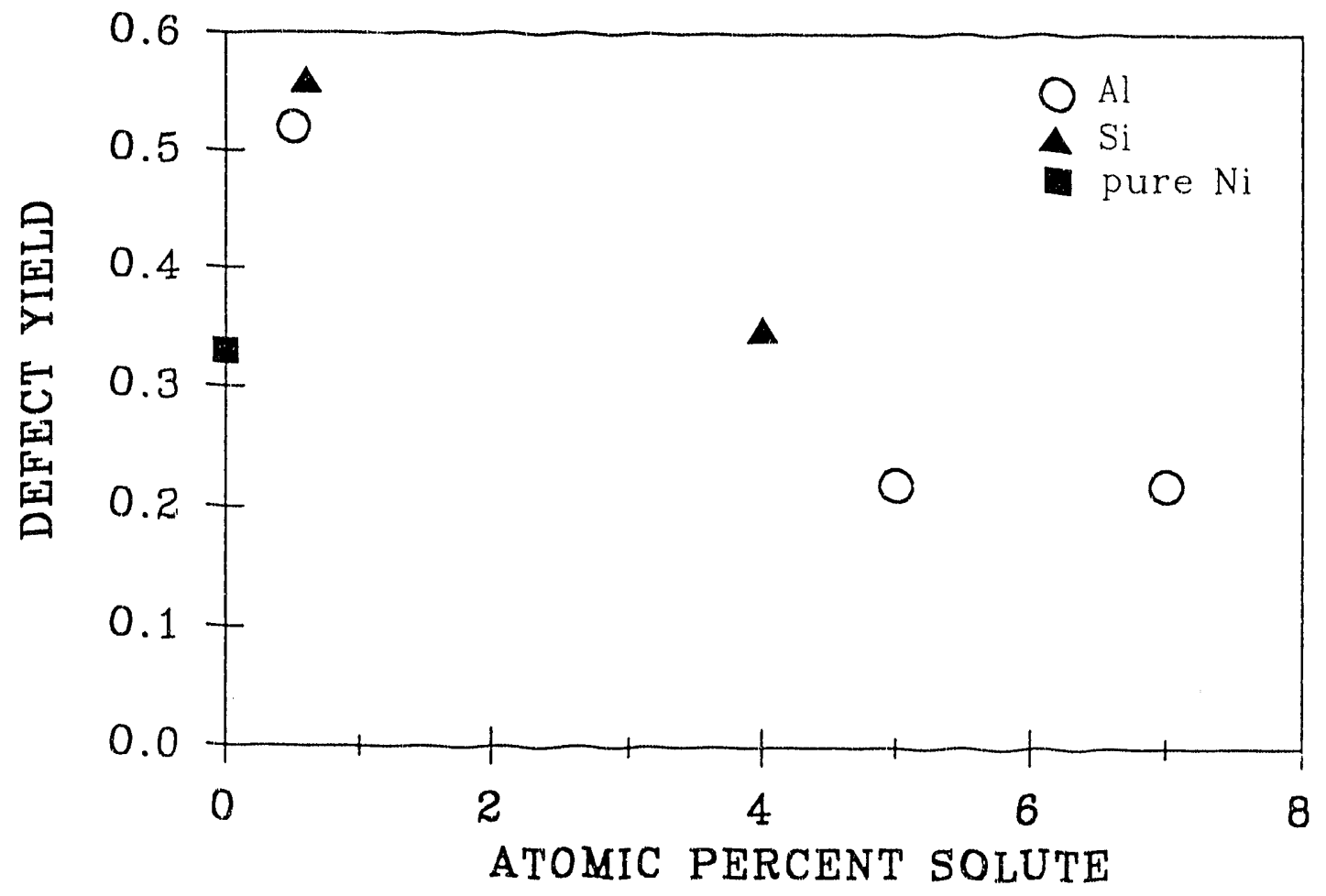

Vetrano et al Fig.. 2 


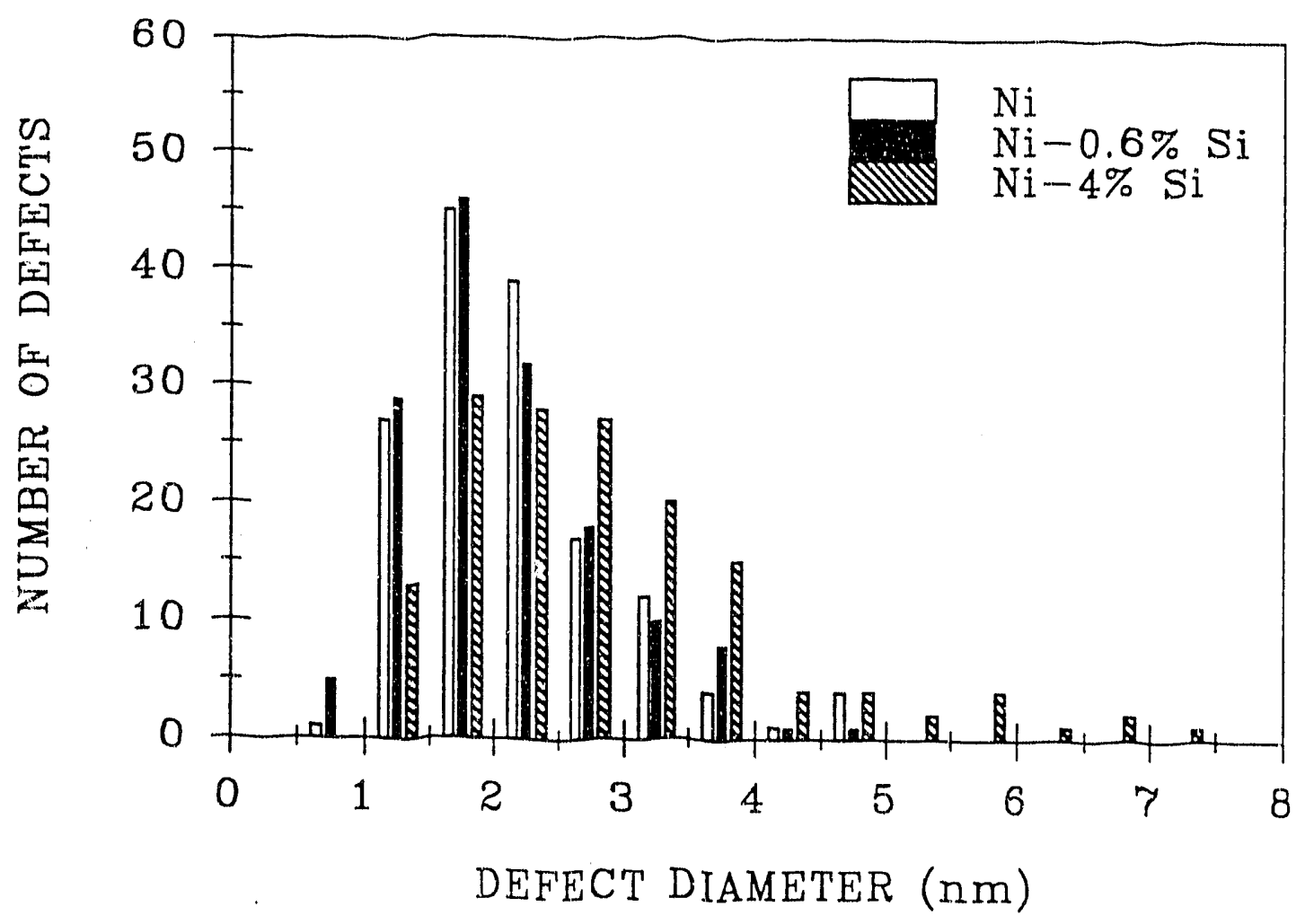

Vetrano et al Fig. 3 


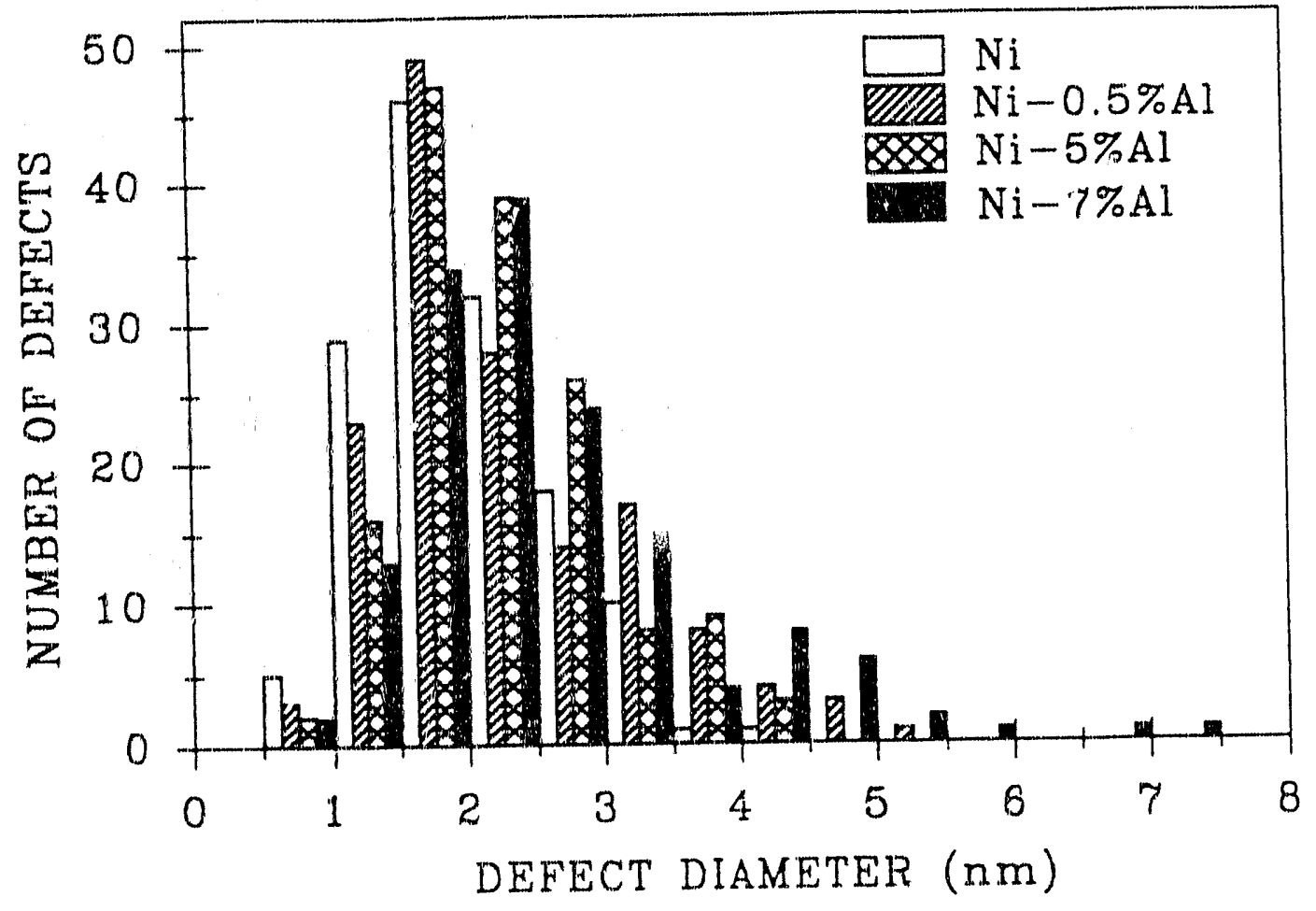

Vetrano et al Fig. 4 

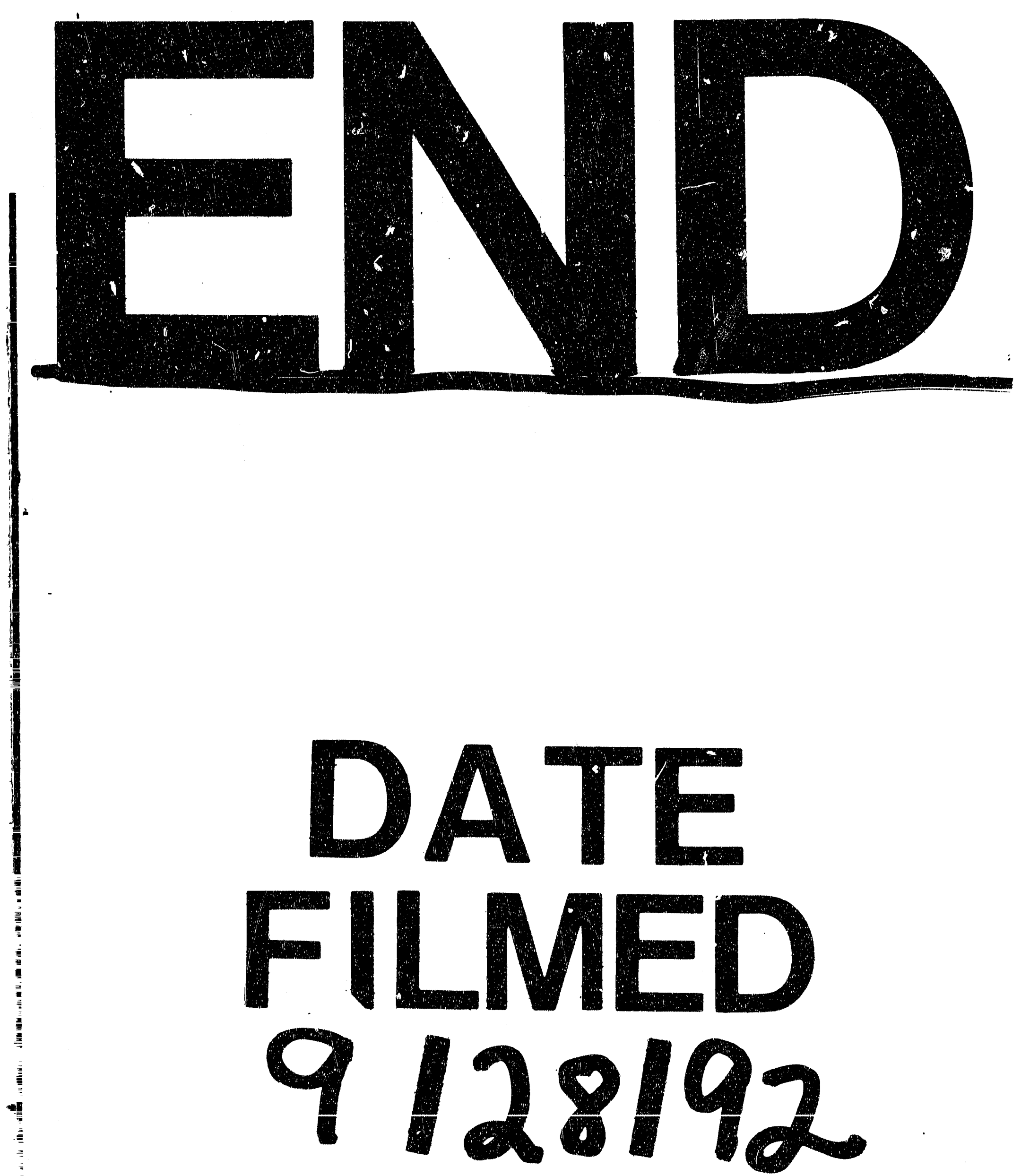
$=$
$=$ 